\title{
Effective e-learning? Multi-tasking, distractions and boundary management by graduate students in an online environment
}

\author{
Jennie Winter $^{\mathrm{a} *}$, Debby Cotton ${ }^{\mathrm{a}}$, Joan Gavin ${ }^{\mathrm{a}}$ and Jon D. Yorke ${ }^{\mathrm{b}}$ \\ ${ }^{a}$ Teaching and Learning Directorate, University of Plymouth, UK; ${ }^{b}$ Office of Teaching and \\ Learning, Curtin University of Technology, Perth, Australia
}

(Received 12 May 2009; final version received 23 July 2009)

This paper reports the findings of a small-scale study that documented the use of information technology for learning by a small group of postgraduate students. Our findings support current knowledge about characteristics displayed by effective e-learners, but also highlight a less researched but potentially important issue in developing e-learning expertise: the ability of students to manage the combination of learning and non-learning activities online. Although multi-tasking has been routinely observed amongst students and is often cited as a beneficial attribute of the e-learner, there is evidence that many students found switching between competing activities highly distracting. There is little empirical work that explores the ways in which students mitigate the impact of non-learning activities on learning, but the evidence from our study suggests that students employ a range of 'boundary management' techniques, including separating activities by application and by technology. The paper suggests that this may have implications for students' and tutors' appropriation of Web 2.0 technologies for educational purposes and that further research into online boundary management may enhance understanding of the e-learning experience.

Keywords: effective e-learning; boundary management; multi-tasking; distractions

\section{Introduction}

e-Learning is increasingly becoming part of the 'core business' of educational institutions. It is credited with having the potential to "improve the quality of learning, improve access to education and training; reduce the cost of education; and improve the cost-effectiveness of education" (Gilbert, Morton, and Rowley 2007, 561), and thus is an attractive option for policy-makers and educators alike. Its potential significance for higher education (HE) in particular was noted in the Dearing Report (NCIHE 1997), which claimed that Internet technology was key to the creation of a learning society and, more recently, in the HEFCE's e-learning strategy that stated "new technologies clearly provide exciting opportunities for enhancement and innovation in learning opportunities" (HEFCE 2005, 5). Despite these policy drivers, however, many institutions are struggling to embed e-learning effectively, and much remains to be learnt about how technology can best be used to enhance student learning.

*Corresponding author. Email: jennie.winter@plymouth.ac.uk 
The continued commitment of HE institutions to e-learning has cultivated a vigorous interest in student perspectives, shedding light on students' experiences of e-pedagogy, infrastructure and technology. Although to date there are few areas of the e-learner experience that have been 'consistently reported' (Sharpe et al. 2005, 3), studies that have documented students' use of technology for learning have reported characteristics that help to define students' effective participation in e-learning (Creanor et al. 2006; Jong-Ki 2008; Sharpe et al. 2005). Research suggests that effective e-learners are often those who demonstrate goal-setting, information-processing, cognitive skills, deep processing skills and decision-making skills. They tend to have high levels of content competence, self-awareness and cognitive empathy to learn collaboratively, as well as appropriate technological skills and the ability to manage their own time (Cramphorn 2004; Jong-Ki 2008). These learners are also likely to have developed contingency strategies and support networks to assist them with technical difficulties (Creanor et al. 2006).

Students who use technology less effectively for learning may lack technical skills or essential learning skills such as sustaining concentration or problem-solving. They may have limited confidence, self-direction or motivation (Lockitt 2004), and in particular are unlikely to have the necessary skills to identify and evaluate appropriate web sources (Dron 2007). Although HE students have been described as 'digital natives' (Prensky 2001), experienced and accustomed to using technologies in their everyday lives, this description is becoming increasingly contentious. There is undoubtedly a wide range of ability and expertise in the current student population, particularly when it comes to using technology for learning (as opposed to social) purposes (Bennett, Maton, and Kervin 2008). It is clear, therefore, that identifying and developing ways to encourage students' effective use of technology for learning are important considerations for those involved in curriculum development and educational innovation.

It is clear that many of the characteristics displayed by effective e-learners are those that are representative of effective learning in general. However, little empirical work has been undertaken that specifically explores the experiences of established learners (those who have demonstrated an ability to learn effectively in other contexts) in order to identify any barriers and drivers to maintaining and continuing the development of e-learning skills. Established learners have broader experiences of learning with and without technology and may be more aware of their own meta-learning strategies than other student groups. It might also be expected that this group of students would have developed sophisticated strategies for negotiating learning in an online environment, therefore investigating their experiences offers the potential for new insights into e-learning.

To investigate these issues further, a research project was undertaken at a large post-1992 university. The project investigated the role that e-learning played as part of the wider experience of a group of graduate students engaged in a campus-based blended learning course. The research explored students' prior experiences and expectations of e-learning, as well as their current uses of technology for learning in order to provide insights into the ways in which technology can be harnessed for maximum educational benefit. The project has generated findings that contribute to debates about the digital divide, the impact of lecturers' prior experiences of technology for eteaching and students' effective use of technology for learning. This paper focuses particularly on the findings relating to effective use of technology. It describes barriers and drivers to developing e-learning 'effectiveness' and documents characteristics that demonstrate effective use of technology for learning. 


\section{Methodology}

Students from two postgraduate courses- the General Teaching Associates (GTA), and the Postgraduate Certificate in Learning and Teaching in Higher Education (LTHE) - participated in the project. These courses combine face-to-face learning with a range of online activities and discussions. The multidisciplinary nature of the courses draws together participants from across the institution's faculties and divisions, representing a wide range of disciplines and backgrounds. Each GTA/LTHE cohort includes approximately 15-25\% international students and a large proportion of students with work and family commitments. Whilst there are limitations to this sample, the selection of these participants makes a positive contribution to the current literature on e-learning, in which postgraduate students' experiences are comparatively under-represented. Moreover, this group represents students who have already demonstrated their success as learners (at the undergraduate level), and so seem likely to provide an opportunity to explore the attributes of effective e-learners (Sharpe et al. 2005).

The research questions were as follows:

- How do the prior experiences and expectations of this diverse group of graduate students affect their participation in and experiences of e-learning?

- What characteristics do effective e-learners display?

- How do these students accomplish learning in the context of competing demands on their time (such as study/work/family commitments)? Which technologies do they choose, and why?

It is the second of these questions on which we focus in this paper. The methodology reflects current good practice in e-learning research, incorporating the purposeful sampling of under-researched groups of learners using open-ended methods and a mixed-mode methodology to explore learners' beliefs, explanations and intentions (Mayes 2006).

\section{Questionnaire}

The questionnaire aimed to create a learner profile by establishing baseline data on technology use. Based on a questionnaire used in the Learner Experiences of e-learning study (Mayes 2006), the questions elicited socio-demographic data (gender, age, etc.), prior experiences and expectations of using technology for learning, and the impacts of e-learning on study, work and family commitments. Closed questions were used, some of which used a six-point Likert scale. Written questionnaires were given to respondents in a face-to-face session and they were asked to complete and return them to the project team within an agreed timescale. There was provision on the questionnaire for respondents to indicate whether they were willing to be interviewed and those who indicated positively were contacted by email and invited to an interview. Thirty questionnaires were completed and returned, providing a response rate of $65 \%$. The data were entered into SPSS and frequency and percentage tables were created.

\section{Semi-structured interviews}

The interviews were semi-structured, using an 'interview plus' approach to enhance discussion (Bloom 1953; JISC 2009). The interview questions focused on four 
themes: prior experiences and expectations; current use of technology for learning; attributes of effective e-learners; and the study-work-family balance. Ten interviews were undertaken, with each lasting approximately one hour. Data were fully transcribed and entered into NVivo. Initial coding was inductive (Thomas 2006) and categories were developed that reflected the question schedule and main trends. The coded data were then reviewed by the research team and a series of key themes were developed by consensus. The data were then re-coded according to the agreed themes, and through this iterative process the project's findings emerged.

\section{Results}

Participants were all graduates and most were either studying for or had completed a $\mathrm{PhD}$. An overview of respondent characteristics is presented in Table 1.

Table 1: Respondent characteristics (frequencies)

The interviews confirmed that participants were highly motivated learners:

I learn everything, I think that you have to use every moment to learn one thing or another ... So it is not just professional planning or getting a degree, just open yourself up to whatever kind of learning. (Male, age 35-54)

However, students' computer skills were, in many cases, limited to using e-mail, Internet searches and presentation software (Table 2), and their experiences of e-learning confined to accessing course materials on computers, video and audio files, computer-based assessment and electronic whiteboards (Table 3). This strongly suggests that, for this group of students, the usual experience of e-learning were those aspects that facilitate traditional lecture-based curricula. This was also evident in students' perceptions of 'e-learning', which were diverse; many felt that it involved little more than the delivery of course content through electronic media, whilst some recognised the opportunities for interaction online:

I would think of e-learning as presentations online. (Male, age 25-34)

E-learning is a good way of exchanging knowledge and interaction between lectures, teachers and students, through the computer and through the internet. (Male, age 25-34)

Overall, there was little support for the idea of learning through technology; rather, participants reported that technology facilitated learning, especially through the procurement of electronic resources:

All I can think is that technology is like an aid to education, for research it is priceless. I don't know if it has helped me learn anything or no, something that I would not have learnt otherwise, I don't know. (Male, age 25-34)

Table 1. Respondent characteristics (frequencies).

\begin{tabular}{lcccccccc}
\hline & \multicolumn{2}{c}{ Age group } & & \multicolumn{2}{c}{ Gender } & & & \\
$\begin{array}{l}\text { Number of } \\
\text { students }\end{array}$ & $\begin{array}{c}24-34 \\
\text { years }\end{array}$ & $\begin{array}{c}35-54 \\
\text { years }\end{array}$ & & Male & Female & $\begin{array}{c}\text { English as } \\
\text { first language }\end{array}$ & $\begin{array}{c}\text { English as } \\
\text { second language }\end{array}$ & $\begin{array}{c}\text { Employed part- } \\
\text { time or full-time }\end{array}$ \\
\hline 30 & 16 & 14 & 20 & 10 & 21 & 9 & 22 \\
\hline
\end{tabular}


The way in which I use e-resources most is the gathering and digesting of information.

(Female, age 25-34)

The interviews, however, revealed a consensus amongst the sample that learning technologies enabled more comfortable, independent and flexible learning. Students reported that technology-enhanced learning in several key ways: not only through access to information, but also access to generic office and subject-specific software, personal organisation, communication, support and making connections.

Interviewees were asked to describe significant barriers and drivers to using technology for learning. Several barriers were reported, which included a lack of prior knowledge and experience, the substantial time and effort required to learn or update skills, financial constraints, accessibility, limitations of current technology and a preference for face-to-face learning. ${ }^{1}$ Drivers included course and employment requirements, time-saving potential, opportunities for career development, and leisure interests. Students experienced different combinations of barriers and drivers that dictated how they utilised e-learning resources and opportunities to enhance learning. However, despite these differences there was evidence that students who made the most effective use of technology for learning purposes were those who: recognised and utilised appropriate e-technologies to meet their own learning needs; networked e-learning support through formal and informal channels; were effective e-communicators; had ongoing opportunities to enhance e-research skills; and developed strategies for managing learning and non-learning activities whilst online.

Table 2. Computer skills.

\begin{tabular}{lc}
\hline e-Activity & Reporting self as expert and proficient (\%) \\
\hline Email use & 83.3 \\
Internet search skills & 70.0 \\
Presentation software use & 50.0 \\
Library search skills & 46.7 \\
Scanner use & 36.6 \\
Spreadsheet use & 23.1 \\
Computer programming & 13.3 \\
Web site development & 13.3 \\
\hline
\end{tabular}

Table 3. Previous experiences of e-learning scenarios.

\begin{tabular}{lc}
\hline Experience & Yes (\%) \\
\hline Course materials on computer & 92.3 \\
Video and audio files & 60.0 \\
Computer-based assessment or tests & 56.7 \\
Electronic whiteboard & 53.6 \\
Online discussion board & 40.0 \\
Face-to-face and online learning & 30.0 \\
Video-conferencing & 26.7 \\
Learning with mobile devices & 6.7 \\
A course delivered only online & 3.3 \\
\hline
\end{tabular}




\section{Recognised and utilised appropriate e-technologies to meet their own learning needs}

All students reported that they felt able to meet their own e-earning needs, which were normally dictated by discipline requirements. In some cases this consisted of email and Internet searches, in others it was more complex activities like programming (Table 2). Students with an information technology (IT) background (either personal or professional) in programming or web creation were observed to choose and apply appropriate e-technologies to different learning scenarios more effectively than other students by recognising the role of technology as a method for learning, and the strengths and limitations of different learning technologies.

\section{Networked e-learning support formally (training) and informally (family and friends)}

Support was cited as an important component of using technology effectively for learning. Although university lecturers and technical staff were identified as possible sources of help, interviewees described generating their own network of friends, family and web-based resources:

Fortunately my brother is an excellent programmer so he was able to give me tutorials about whatever I needed for free. (Male, age 25-34)

The data again suggest a distinction between students who have a background in IT and are therefore more likely to use web-based support and those who instead build support networks consisting mainly of significant individuals:

Everything has got a tutorial somewhere and that is how I have done it before and tutorials will usually get you started. There are never bits of IT or software there without any help; so I probably would use e-learning to learn. (Female, age 35-54)

\section{Were effective e-communicators}

The sample demonstrated high levels of expertise for e-communication particularly through the use of email to sustain relationships with colleagues, to facilitate learning through contacting key individuals and organisations, and to maintain a digital presence connected to mailing lists, journal alerts, conference invitations and other academic activity (Table 2 ).

They send me e-mails through Google Scholar. They remind me if there are new papers about topics in the area of my research or any new publications. If a friend has a paper which he finds interesting he will email it to me. (Male, age 35-54)

I hassle people [through email] for help with the things I am stuck on. There are also a lot of mailing lists that you can get information from. If it looks interesting then I will read it. (Female, age 25-34)

Although there was less evidence of students using alternative online communications such as discussion boards and video-conferencing (Table 3), having prior experience of blended learning was an important predictor of their subsequent interest or engagement in these activities. It was evident that students' perceptions 
of e-communication were dependent on previous experience and this was particularly apparent when documenting student participation in the online asynchronous discussions (OADs), which formed part of the GTA and LTHE courses. Students who had previous experience of OADs described barriers to participation, including: lack of tacit understanding between contributors, the perceived need for originality with every posting, time constraints, access, spelling and grammar, and contributing to a text in the group or public domain. However, these students also acknowledged benefits such as the opportunities for reflection, expressing opinion and sharing ideas. The students who had the most experience of using OADs for learning purposes were those who either had a background in IT and used these forums to swap code or were international students and used forums to maintain contact with former colleagues. There was evidence that students who had not previously participated in OADs could be doubtful about the possible benefits for learning and be reticent to participate:

I do not necessarily see the advantages of a discussion forum. I suppose my problem with this is that in my day when I was at university [as an undergraduate] we did not have any on-line forums as such as those have evolved in the last few years so it is a bit difficult to see what the advantage is. (Male, age 25-34)

However, participants were often more favourable about using OADs after participation in the GTA/LTHE online activities.

\section{Had ongoing opportunities to enhance academic research skills}

Academic research skills were seen as essential for maximising the resource opportunities made possible by learning technologies. Students' views of relevant research skills fell into two categories: using the Internet to search for material, and ability to use a range of technologies for research purposes. Using Internet searches for research was common practice for $70 \%$ of the sample. What was less easy to determine was how students validated the resources they located online: There was substantial variation in awareness of available e-resources and also in the strategies employed for making judgements about academic robustness. Strategies included: restricting sources to peer-reviewed e-journals; evaluating the reputation of the author by checking prior career activity and professional associations; verifying authentication with peers and managers; and observing URL endings (.com, .org and .ac). In terms of being competent in using a range of technologies to undertake research, students used a range of (discipline specific) software and hardware for which different sets of skills had to be learnt and intermittently updated. Participants appreciated that academic research skills needed to be continually adapted to keep pace with changes in the storage, retrieval and delivery of information. Although learning new technologies was welcomed by students, updating skills was perceived as time consuming and frustrating. The need to update was promoted by several factors, including course requirements, department cultures, job requirements, time-saving initiatives and personal interest in IT.

\section{Developed strategies for managing learning and non-learning activities whilst online}

Many students reported having non-learning activities embedded within their personalised e-learning environment when using computers for learning purposes. For 
example, many routinely used applications such as Messenger, Facebook, Skype and newspapers alongside writing, reading and other learning applications. Examining the data for contrasts by age showed that younger students enjoyed social networking sites to a greater degree and were more likely to be using them whilst engaged in learning, whereas older students were more likely to be using online current affairs resources. Some reported flicking frequently between learning and non-learning activities.

Well, invariably I will have my university e-mail account open and my hotmail open as well and sometimes maybe Facebook or something like that as well. Normally if I am typing then every few minutes I will flip back because I chat a lot to my mates during the day and we email each other. (Male, age 25-34)

Some students attempted to maintain boundaries between learning and non-learning activities through the use of distinct applications. For example, learning was generally associated with Microsoft Office applications and 'academic' software; social activities were often associated with personal email accounts, Facebook, and other Web 2.0 applications. Despite the construction of these conceptual-technological boundaries, a number of students reported that non-learning applications distracted them from learning. This led to a range of further strategies being used to manage learning and non-learning activities. Although individual circumstances and strategies varied, common examples included choosing to learn away from computers, disabling e-mail and other alerts and other adjustments to working practices:

No, of course I do not have my computer on when I am trying to learn because sometimes this distracts me because I have the Messenger on or I will read the newspapers and I don't like that if I am trying to learn. (Male, age 25-34)

I refuse to have Messenger on, I used to have it before so it is always tempting 'you have a message, a message' so I deleted it ... so that I can concentrate on learning more. (Male, age 35-54)

I don't check my email in the day, not until the evening, everybody knows I only check it later in the day because it's too distracting. (Male, age 35-54)

It is clear that students were concerned both about the potential impact of 'social' distractions on their academic work, but also about the impact of academic work impinging on their social space. Several students voiced resistance to the appropriation of what they considered to be 'personal' technologies, such as mobile phones and MP3 players, for learning purposes. The potential implications of this are discussed later.

One of the things suggested was to record myself onto an MP3 player but I don't want to put my MP3 player onto 'mix' and in the middle of listening to tracks have this dull voice taking about law. That is my play time when I listen to my MP3 ... there has to be a distinction between leisure and work. (Female, age 25-34)

I have ... got a hotmail account which I have had for a few years and then my university one ... one is for leisure, so the hotmail is just for emailing my friends really ... So they are two separate things. One is work and one for socialising. (Male, age 25-34) 
Despite the strategies outlined above, it is clear that many students surfed between learning and non-learning activities throughout the day. Solutions were rarely permanent and always at the discretion of the learner. This suggests that whilst students expressed a preference for strong conceptual boundaries between learning and non-learning activities, in practical terms few were able to compartmentalise competing tasks for extended periods that some reported as distracting. This had wider implications for students' perceptions about where and how they learnt best. For example, over one-half of the interviewees reported that they learnt most effectively away from information and communications technologies when reading on their own, suggesting that ideas of study as an isolated, individual activity were prevalent.

\section{Discussion}

Learners in this study displayed characteristics representative of an e-learning skills base, which has been recognised by several authors (Creanor et al. 2006; Jong-Ki 2008; Sharpe et al. 2005). These skills are also indicative of those required for effective learning in the wider pedagogic literature (Ertmer and Newby 1996), reflecting the sample group's status as established learners. Students who used technology effectively for learning were able to choose suitable resources, to use them at an appropriate level, to access support from others, and to communicate effectively using technology. Although there were marked differences in students' abilities and experiences, all students reported having sufficient skills to meet their own e-learning needs. However, this study also identified recurring problems with learning online, even amongst these 'effective' e-learners. These included issues around validating online resources, uncertainty about online discussions, and difficulty in managing the boundary between the academic and the social sphere.

The findings raise questions about how students learn to navigate the Internet and validate the information they retrieve. Previous research has highlighted informationseeking behaviour of students as key to the successful fusion of technology and learning (Dron 2007). The CIBER $(2008,19)$ project explored student informationseeking behaviour and concluded that it is impeded by the sheer quantity of information available, the constant updating of choice by search engines and the reluctance of students to read through material online, all of which contribute to 'dumbing down' the academic robustness of the sources students elect to use (CICLE 2009). The validation of web content is a fundamental skill for HE students and for fulfilling the broader remit of e-literacy (Pilerot 2006). Students learnt to evaluate content through a mixture of formal training, intuition and heuristics, specific to their subject area. However, for students to be able to understand, evaluate and critique the production and management of knowledge, they require strategies to enable them to operate both within and beyond their discipline. This suggests that an emphasis on the evaluation and validation of online academic resources may enhance students' research skills.

The paper also sheds light on how different disciplines promote e-learning skills. IT students were identified as a group with broader experiences of using technologies for learning and better able to identify the benefits and limitations of those technologies than students from other disciplines. Research on learner differences and the ability to become an effective e-learner has explored the impact of gender (Cox et al. 2000), culture and language (Jones et al. 2004). However, there has been less work to date that has considered the potential benefits of distinct discipline praxis to the 
e-learning agenda (CIBER 2008; Conole et al. 2006) with a view to exporting good practice across the wider HE environment. Furthermore, the research reminds us that despite claims that email has been eclipsed by Web 2.0 (Nelson 2006), it remains a highly popular mode of communication and is widely used to facilitate learning.

In addition to findings that support established literature, the paper also identifies issues that have been relatively unexplored empirically; most significantly, the potential impacts of managing learning and non-learning tasks in an online environment. Many of the learners in our sample believed that frequently changing focus was distracting and detrimental to learning. Although there has been little previous educational research on managing non-learning and learning tasks in online environments, other disciplines are rich in debates about the impacts of multi-tasking on students' ability to learn. In psychological and neurological research there is evidence that undertaking more than one activity simultaneously promotes short attention spans (Oblinger 2005) and that complex learning tasks requiring high levels of attention will be affected to a greater degree (Koechlin et al. 1999). This suggests that, in general, single-task learning may be most conducive to deep learning. However, Zhong, Dijksterhuis, and Galinsky (2008) suggest that deliberately distracting learners from tasks can, in some conditions, actually enhance the learning process. Their findings indicate that conscious thought is better for making linear, analytic decisions, whereas unconscious thought (generated through the process of distraction) can be effective for solving complex problems. In the light of these competing accounts, our findings raise questions about what combination of learning and non-learning activities is optimal and to what extent students are able to recognise their vulnerability to distraction, and develop appropriate management schemas and strategies.

The technique of 'boundary management' (Nippert-Eng 1996) employed by some of the students in this study is also of interest. All respondents cited managing learning and non-learning tasks online as challenging, and over one-half reported that they learnt most effectively when reading individually away from computers. Reading is, of course, critical for academic, cognitive and communication development (Harrison 2004) and it is also pertinent that this and previous studies reported students' preference for reading printed copy rather than on-screen (Cotton and Gresty 2008). However, in their preference for traditional rather than online learning, many of these students failed to recognise or value the potential opportunities for collaborative online learning, and instead used networking and communication tools almost entirely for social purposes. It is therefore possible that strategies for separating learning and non-learning tasks may make students reticent to use Web 2.0 for learning purposes (since these are construed as social technologies). Some evidence in support of this theory is available in the literature. For example, the JISC-funded 2007 IPSOS MORI report into student expectations of information and communications technology use in HE reveals that, despite high levels of personal Web 2.0 use, students fail to see how social networking can be used as a learning tool and furthermore are cautious about doing coursework online (Dutton and Helsper 2007). In a similar vein, the literature on OADs, which have the potential to enhance opportunities for collaborative learning, is saturated with descriptions of student-led barriers to participation (Gilbert, Morton, and Rowley 2007). Nonetheless, e-learning is ubiquitous in the student experience and potentially offers a wealth of collaborative learning opportunities and interactive possibilities as identified by Thorpe (2008). Moreover, given that much student study time is likely to involve computer use, investigating strate- 
gies for boundary management in the online environment appears an area worthy of further research.

\section{Recommendations}

The findings of this research suggest the following to improve students' use of technology for maximum educational benefit:

- Encouraging students to use web-based support by clearer signposting of online tutorials, guidance and discussion boards. This will help to strengthen the support networks that students create for themselves.

- Enhancing students' awareness and understanding of meta-learning strategies in an online environment (and elsewhere).

- Embedding OADs more commonly in campus-based blended learning initiatives. These provide a valuable tool for broadening students' experience of alternative forms of communication and participation often improves students' perceptions of the possibilities for learning through interaction.

- Evaluate and reward Internet-based research skills within assessment. Ensuring that students use critical thinking skills to evaluate Internet resources is a key challenge for HE.

Although this research was undertaken with postgraduate students, the recommendations suggest several research possibilities that could include other student groups. Research identifying the specific skills which IT students possess, enabling them to use technology effectively for learning, could provide valuable insights into a potentially generic skills base for e-literacy. In addition, research that explicitly sets out to investigate the impacts of boundary management strategies on learning is recommended - to explore the perceptions students have about using technology for learning, and to investigate the ways in which students conceptualise the difference between technologies for learning and socialising. The fundamental question remains, however: are these distinctions that can be blurred by successful e-learners or e-tutors, or should effective learners be encouraged to separate these activities entirely?

\section{Conclusion}

This paper has documented the e-learning experiences of a group of graduate students. The findings suggest that most students in this study were able to use technology to meet their own learning needs, but that these needs vary from learner to learner. It was also evident that 'effective e-learners' share many of the characteristics of effective learners in general. The study revealed that studying in an online environment brought with it a number of advantages but also some potential pitfalls, most particularly that of managing learning and non-learning activities and the implications this appears to have for students' perceptions about effective (or deep) learning. The findings also suggest that learners separate learning and non-learning activities by technology and software application, which may hold some explanatory power when investigating student reticence towards Web 2.0 learning. The paper concludes by suggesting that further research into students' strategies for separating learning and non-learning tasks online might enhance understanding of the e-learner experience and contribute to the task of improving teaching and learning in HE. 


\section{Notes}

1. In the questionnaire, $66.6 \%$ of the sample expressed a preference for face-to-face learning over online learning.

\section{References}

Bennett, S., K. Maton, and L. Kervin. 2008. The 'digital natives' debate: A critical review of the evidence. British Journal of Educational Technology 39, no. 5: 775-86.

Bloom, B.S. 1953. Thought processes in lectures and discussions. Journal of General Education 7: 55-71.

CIBER. 2008. Information behaviour of the researcher of the future. CIBER briefing paper. UCL. http://www.jisc.ac.uk/media/documents/programmes/reppres/gg_final_keynote_ 11012008.pdf.

CICLE. 2009. Higher education in a Web 2.0 world. Report by the Committee of Inquiry into the changing learner experience. CICLE. http://www.jisc.ac.uk/media/documents/publications/heweb20rptv1.pdf.

Conole, G., M. de Latte, T. Dillon, and J. Darby. 2006. Student experiences of technologies: Draft final report. JISC LXP. http://www.jisc.ac.uk/media/documents/programmes/elearningpedagogy/lxp_project_final_report_nov_06.pdf.

Cotton, D.R.E., and K.A. Gresty. 2008. Barriers to student engagement with educational technology: Insights from a 'think aloud' study. In New Educational Technology, ed. R. Kobayashi, 149-64. New York: Nova Science Publishers.

Cox, E.S., W.P. Clark, H. Heath, and B. Plumpton. 2000. The impact of gender on effective online discussion groups. Paper presented at the Distance Education: An Open Question? Conference, September 11-13, in University of South Australia. http://www.unisanet.unisa.edu.au/cccc/papers/refereed/paper12/Paper12-1.htm.

Cramphorn, C. 2004. An evaluation of the formal and underlying factors influencing student participation with e-learning web discussion forums. Paper presented at the Networked Learning Conference, April 5-7, in Lancaster, UK.

Creanor, L., K. Trinder, D. Gowan, and C. Howells. 2006. LEX The Learner Experience of e-Learning: Final project report. Glasgow: Glasgow Caledonian University.

Dron, J. 2007. Control and constraint in e-learning: Choosing when to choose. London: Idea Group Publishing

Dutton, W.H., and E.J. Helsper. 2007. The internet in Britain. Oxford: Oxford Internet Surveys, Oxford Internet Institute, University of Oxford.

Ertmer, P.A., and T.J. Newby. 1996. The expert learner: Srategic, self regulated, and reflective. Instructional Science 24: 1-24.

Gilbert, J., S. Morton, and J. Rowley. 2007. E-learning: The student experience. British Journal of Educational Technology 38, no. 4: 560-73.

Harrison, C. 2004. Understanding reading development. London: Sage.

HEFCE. 2005. HEFCE strategy for e-learning. JISC/HEA. http://www.hefce.ac.uk/pubs/ hefce/2005/05_12/05_12.pdf.

JISC. 2009. JISC learner experience phase 2: Interview plus. https://mw.brookes.ac.uk/ display/JISCle2/Interview+plus.

Jones, P., G. Packman, C. Miller, and A. Jones. 2004. An initial evaluation of student withdrawals within an e-learning environment: The case of e-college Wales. Electric Journal of e-Learning 2, no. 1: 113-20.

Jong-Ki, K. 2008. The effects of LMS quality and e-learners characteristics regarding e-learner's scholastic performance: A proposal for e-learning success model. Proceedings from ASBBS 15, no. 1: 34-45.

Koechlin, E., G. Basso, P. Pietrini, S. Panzer, and J. Grafman. 1999. Exploring the role of the anterior prefrontal cortex in human cognition. Nature 399, no. 6732: 148-51.

Lockitt, B. 2004. Adult, community and work based learning: e-learning. Cheadle, UK: 3 T productions.

Mayes, T. 2006. LEX: The learner experience of e-learning methodology report. Glasgow: Caledonian University. 
NCIHE. 1997. Higher education in the learning society: The Dearing report. National Committee of Inquiry into Higher Education. London: HMSO.

Nelson, M. 2006. Lessons from the real world. Paper presented at the TERENA Conference, May 15-18, in Catania, Italy. http://www.terena.nl/events/tnc2006/programme/presentations/show.php?pres_id=176.

Nippert-Eng, C. 1996. Calendars and keys: The classification of 'home' and 'work'. Sociological Forum 11: 563-83.

Oblinger, J. 2005. Educating the net generation. https://www.msmc.la.edu/Include/learning resources/todays learner/OneDayv2-HO.pdf.

Pilerot, O. 2006. Information literacy: An overview. In Digital literacies for learning, ed. A. Martin and D. Madigan, 80-8. London: Facet.

Prensky, M. 2001. Digital natives, digital immigrants. On the Horizon 9, no. 5: 1-6.

Sharpe, R., G. Benfield, E. Lessner, and E. DeCicco. 2005. Scoping study for the pedagogy strand of the JISC e-learning programme. JISC. http://www.jisc.ac.uk/elp_learnerout comes.html (accessed March 18, 2010).

Thomas, R. 2006. A general inductive approach for analysing qualitative evaluation data. American Journal of Evaluation 27, no. 2: 237-46.

Thorpe, M. 2008. Effective online interaction: Mapping course design to bridge from research to practice. Australasian Journal of Educational Technology 24, no. 1: 57-72.

Zhong, C.B., A. Dijksterhuis, and A. Galinsky. 2008. The merits of unconscious thought in creativity. Psychological Science 19, no. 9: 912-8. 